\title{
PENGGUNAAN APLIKASI SCHOOLOGY PADA SMARTPHONE UNTUK MENINGKATKAN MINAT BELAJAR KIMIA SISWA SMA PUSAKA 1 JAKARTA
}

\author{
Nova Irawati Simatupang ${ }^{1 *}$, Fenny Maria'), Elferida Sormin ${ }^{1)}$ \\ 1) Program Studi Pendidikan Kimia Universitas Kristen Indonesia \\ *e-mail:nova@uki.ac.id.
}

\begin{abstract}
This research aims to: (1) to find out whether there is an increase in students' interest in learning chemistry through the use of Schoology applications. (2) to find out how much increased interest in learning chemistry students through the use of Schoology applications. The type of research used is the quantitative description. Sampling technique, namely purposive sampling, the sample divided into two classes, namely the control class 38 students and the experimental class 38 students. The innovative course taught using a guided inquiry learning model utilizing application Schoology, while the control class uses a guided inquiry learning model without the application. The research instrument in the form of a questionnaire the scale of measurement using a Likert scale. Hypothesis testing using a paired sample $t$ test with a significance of 0.05 obtained the results of $t_{\text {count }}(5.561)>t_{\text {table }}(2.377)$ and significant value of $0.00<0.05$. Based on data analysis and hypothesis testing assisted by SPSS for Windows Version 22.0, that there was an increase in students' interest in learning chemistry through the use of Schoology applications. To find out how much increased interest in students learning through the use of application Schoology by using the gain test results obtained at $35.5 \%$ in the medium category.
\end{abstract}

\section{Keywords: chemistry, interest in learning, Schoology, smartphone}

\begin{abstract}
Abstrak
Penelitian ini bertujuan untuk: (1) mengetahui apakah ada peningkatan minat siswa dalam belajar kimia melalui penggunaan aplikasi schoology. (2) mengetahui seberapa besar peningkatan minat belajar kimia siswa melalui penggunaan aplikasi schoology. Jenis penelitian yang digunakan adalah deskripsi kuantitatif. Teknik pengambilan sampel yaitu purposive sampling, dimana sampel dibagi menjadi 2 kelas yaitu kelas kontrol yang terdiri dari 38 siswa dan kelas eksperimen sebanyak 38 siswa. Kelas eksperimen diajarkan menggunakan model pembelajaran inkuiri terbimbing menggunakan sekolah aplikasi, sedangkan kelas kontrol menggunakan model pembelajaran inkuiri terbimbing tanpa aplikasi. Instrumen penelitian yang digunakan adalah angket dengan skala pengukuran menggunakan skala likert. Pengujian hipotesis menggunakan paired sample t-test dengan signifikansi 0,05 diperoleh hasil thitung $(5,561)>$ ttabel $(2,377)$ dan nilai signifikan $0,00<0,05$. Analisis data dan pengujian hipotesis dilakukan dengan berbantukan SPSS untuk Windows Versi 22.0. Berdasarkan analisis diketahui bahwa ada peningkatan minat siswa dalam mempelajari kimia dengan menggunakan aplikasi schoology. Adapun besar peningkatan minat belajar kimia siswa setelah menggunakan aplikasi schoology yang dihitung dengan hasil tes gain diperoleh sebesar 35,5\% yang diklasifikasi dalam kategori sedang.
\end{abstract}

Kata Kunci: kimia, minat belajar, schoology, smartphone

\section{PENDAHULUAN}

Pembelajaran menurut UU Sisdiknas No. 2 Tahun 2003 yang menyatakan bahwa pembelajaran merupakan interaksi antara pendidik, peserta didik, dan sumber belajar dalam lingkungan belajar tertentu, di mana setiap unsur yang terlibat dalam pembelajaran tersebut dapat dicirikan dengan pembelajaran yang berpusat pada siswa (student centered learning). 
Indonesia saat ini sedang memasuki masa revolusi industri 4.0, di mana masa tersebut sangat mengunggulkan teknologi digital seperti komputer, laptop, gadget atau smartphone. Kemajuan teknologi dalam dunia pendidikan perlu diperhatikan, karena pada masa yang akan datang pendidikan menjadi kunci keberhasilan dan kemajuan Indonesia. Menurut konsultan Education Sector Analytical and Capacity Development Partnership (ACDP), Linggasari (CNN Indonesia, 2015) mengemukakan bahwa jika dilihat dalam pelaksanaannya, pemanfaatan teknologi dalam pendidikan masih kurang optimal, karena terdapat faktor lain yang mempengaruhi hal tersebut yaitu kurangnya pelatihan bagi guru dalam menggunakan teknologi, tidak sepenuhnya guru dapat memanfaatkan komputer dan internet dengan maksimal, pemerataan sarana dan prasana yang belum menyeluruh diberbagai daerah, dan kurangnya dukungan untuk pemeliharaan alat.

Penggunaan smartphone atau telepon pintar di masa revolusi industri 4.0 mengalami peningkatan yang begitu pesat dengan daerah penyebarannya paling besar di daerah kota dengan pengguna smartphone mencapai $70,96 \%$ sedangkan di desa mencapai $42,06 \%$. Namun pemanfaatan dalam penggunaan smartphone masih didominasi dengan sebatas aplikasi chatting sebesar $89,35 \%$ dan sosial media sebesar $87,13 \%$. Durasi penggunaan internet per hari atau pekan, yang paling besar menggunakan internet dalam sehari dengan durasi 1-3 jam, yakni 43,89 persen, kemudian durasi 4-7 jam sebesar 29,63 persen, dan di atas 7 jam sebesar 26,48 persen (APJII, 2018).

Menurut Wakil Ketua tim pelaksana Dewan TIK Nasional Detiknas, Hasibuan (Kompas, 2012) mengatakan bahwa penggunaan smartphone sebatas untuk media sosial seperti facebook dan twitter dan kepemilikan smartphone yang serupa dengan jumlah penduduk di Indonesia, sehingga pemanfaatan smartphone masih kurang efektif dalam pembelajaran, di mana jejaring sosial yang dimanfaatkan hanya untuk narsis, padahal seharusnya smartphone dan sosial media dapat digunakan untuk mendorong produktivitas dan memudahkan guru dan peserta didik untuk menambah pengetahuan tanpa batas, dengan hal tersebut pemanfaatan dari penggunaan smartphone lebih positif dan lebih efektif. Senada dengan penelitian yang mengemukakan bahwa realita yang terjadi sebagaian besar peserta didik menggunakan smartphone hanya untuk telepon, SMS, dan chatting. Belum banyak yang digunakan untuk pemanfaatan pembelajaran dalam dunia pendidikan (Pratama, 2018).

Berdasarkan pengalaman yang peneliti lakukan selama Praktik Keterampilan Mengajar (PKM) di SMA Pusaka 1 Jakarta, siswa kelas $\mathrm{X}$ di kelas hanya mau menerima ilmu, pengetahuan, dan informasi dari pendidik saja dan siswa tidak mau bertanya kepada guru selama pembelajaran berlangsung, karena siswa tersebut memfokuskan diri kepada gadget atau smartphone yang mereka miliki. Siswa juga diperbolehkan membawa smartphone ke sekolah, jika dilihat penggunaan smartphone di kelas membuat siswa jadi lebih tertarik menggunakan smartphone untuk bermain game dan membuka sosial media lainnya daripada belajar di kelas, sehingga minat belajar siswa rendah karena siswa lebih tertarik bermain game dan malas untuk belajar. Melalui hasil observasi melalui penyebaran angket minat belajar kimia kepada siswa, dapat dikatakan tergolong rendah dengan persentasi sebesar 37,5\%, maka dari itu pengalihan dalam penggunaan smartphone siswa di kelas yang hanya sebatas bermain game dan membuka sosial media kearah yang lebih positif, dengan menggunakan smartphone siswa menjadi media pembelajaran, melalui smartphone siswa bisa belajar di kelas dengan maksimal dan meningkatkan minat belajar siswa di kelas.

Menurut Djamarah (2015:166) minat yang merupakan perasaan senang dan ketertarikan terhadap suatu kegiatan, tanpa ada paksaan. Pada dasarnya minat menggambarkan penerimaan suatu hubungan antara diri sendiri dengan proses. Di mana proses tersebut dapat dipengaruhi dengan adanya respon yang diberikan. Jika semakin besar hubungan tersebut, maka semakin besar minat yang diciptakan dalam dirinya. 
Seseorang akan belajar lebih baik ketika menggunakan media belajar yang sesuai, sehingga siswa dapat memperoleh hasil belajar yang lebih baik. Hal ini terjadi karena penggunan media dapat memberi stimulus untuk meningkatkan minat belajar siswa pada materi yang dipelajari (Simatupang, 2020). Ada banyak media pembelajaran berbasis online atau $e$ learning yang dapat dilakukan dalam proses pembelajaran salah satunya schoology. Schoology merupakan media yang memudahkan guru dalam memberikan kesempatan untuk siswa agar melakukan komunikasi yang luas dan agar siswa dapat lebih mudah berdiskusi dan kerjasama dalam tim. Fitur quiz yang tersedia dalam schoology menyediakan macam-macam jenis soal yang dapat diaplikasikan oleh guru dan siswa dalam menyajikan soal tes secara online bagi siswa. Schoology membantu guru dan siswa dalam menyajikan, mendistribusi materi, serta mengevaluasi soal secara praktis dan sangat efisien saat digunakan menurut Friedman, dkk (dalam schoology.com, 2018).

Dengan kelebihan yang dimiliki oleh media schoology, media ini cocok digunakan untuk pembelajaran kimia yang menurut siswa membosankan, sulit dipahami karena agar dapat memahami konsep pembelajaran kimia harus dikaitkan dengan kehidupan sehari-hari dan dalam penyelesaian soal kimia harus dilakukan berulang-ulang dengan mengadakan kuis untuk melatih siswa. Adapun materi pada pembelajaran kimia yang dapat diajarkan dengan aplikasi schoology adalah materi stoikiometri.

Menurut pendapat Slameto (2015) minat belajar dapat diungkapkan melalui suatu pernyataan yang menunjukkan bahwa siswa lebih menyukai sesuatu hal ketimbang hal yang lain. Siswa yang memiliki minat akan suatu hal tertentu lebih cenderung untuk memberikan perhatian yang lebih besar terhadap sesuatu hal tersebut. Minat belajar menurut Rahmat (2018) adalah bentuk di mana seseorang memberi perhatian yang diikuti dengan keinginan guna mengetahui, mempelajari, memiliki, dan membuktikan. Menurut Slameto (2015) minat belajar meliputi beberapa aspek yaitu sebagai berikut: (1) perasaan senang (2) ketertarikan (3) penerimaan dan (4) keterlibatan siswa. Dari definisi yang dikemukakan mengenai indikator minat belajar, sedangkan menurut Rahmat (2018:162) indikator minat belajar yang meliputi: (1) perasaan senang (2) adanya perhatian (3) keaktifan dalam melakukannya.

E-learning menurut Prawiradilaga (2016) merupakan istilah baru dari penggunaan teknologi elektronik untuk menyampaikan pembelajaran. Teknologi yang dapat digunakan berupa komputer, internet maupun intranet serta teknologi elektronik lain seperti audio/radio, gadget atau smartphone dan video/televisi. Karakteristik dari e-learning yaitu dengan adanya institusi yang menyelenggarakan, sistem pengelolaan yang jelas, materi atau bahan yang dipelajari dan subjek yang mempelajarinya, strategi (proses pembelajaran) yang diberlakukan, ada teknologi komunikasi yang dipilih dan digunakan, sistem layanan bantuan, dan aturan main (etika) yang diberlakukan.

Adapun aplikasi perangkat lunak yang dapat digunakan untuk dokumentasi, administrasi, pelacakan, pelaporan program pelatihan, kelas dan kegiatan yang berbasis daring "online", "e-learning program" yang terdapat di learning management system (LMS), di mana terdapat program aplikasi LMS antara lain Moodle, Schoology, dan Edmodo. Aplikasi yang dimanfaatkan dalam penelitian ini adalah Schoology.

Menurut Tigowati (2017) inovasi dari Schoology platform terinspirasi dari facebook memberikan fitur mendasar dengan adanya post, update status, dan berbagi tautan yang bertujuan untuk menjadikan aplikasi tersebut sebagai alat belajar. Schoology adalah akun sosial yang dapat digunakan pribadi untuk guru dan siswa dengan platform sosial yang aman. Schoology merupakan salah satu laman web yang berbentuk web sosial di mana menyediakan fitur pembelajaran yang sama seperti di dalam kelas dan sangat mudah digunakan seperti saat menggunakan facebook, dengan schoology guru dimudahkan dalam mengurus pembelajaran.

Dalam perannya menurut Friedman, dkk (dalam schoology.com, 2018) schoology membantu guru dalam membuka kesempatan komunikasi yang luas kepada siswa agar siswa 
dapat lebih mudah untuk diskusi dan kerjasama dalam tim. Schoology dapat memberikan pembelajaran dengan siswa di luar kelas atau di luar jam pelajaran. Didukung oleh berbagai bentuk media seperti video, audio da image dan audio, sehingga melalui schoology diharapkan dapat menjawab permasalahan yang ada di kelas. Schoology adalah aplikasi Learning Management System (LMS) yang dapat digunakan secara online dan dapat diakses oleh guru dan siswa secara gratis.

\section{METODE}

Penelitian ini menggunakan pendekatan deskriptif kuantitatif, artinya data yang dikumpulkan tidak hanya berupa data angka melainkan data yang berasal dari hasil catatan peneliti. Penelitian dilaksanakan di SMA Pusaka 1 Jakarta terletak di Jl. Pahlawan Revolusi Gang Taruna No. 89 RT.006/RW.4, Kelurahan Pondok Bambu, Kecamatan Duren Sawit, Jakarta Timur.

Populasi dalam penelitian ini adalah seluruh siswa kelas X di SMA Pusaka 1 Jakarta T.A 2018/2019. Sampel penelitian adalah kelas X IPA di SMA Pusaka 1 Jakarta terdiri dari kelas X IPA 1 berjumlah 38 siswa dan kelas X IPA 2 berjumlah 38 siswa, sehingga jumlah keseluruhan sampel sebanyak 76 siswa. Berdasarkan penentuan sampel, teknik pengambilan sampel yang dilakukan adalah purposive sampling dengan pertimbangan karena kelas X IPA hanya terdapat dua kelas yaitu IPA 1 dan IPA 2.

Desain eksperimen yang digunakan adalah quasi experimental design (eksperimen semu). Bentuk desain quasi experiment yang digunakan adalah nonequivalent control group design (Sugiyono, 2013).

Tabel 1. Desain Penelitian

\begin{tabular}{llll}
\hline Kelas & Pre-nontest & Perlakuan & Post-nontest \\
\hline Eksperimen & $\mathrm{O} 1$ & $\mathrm{X}_{\mathrm{E}}$ & $\mathrm{O} 2$ \\
\hline Kontrol & $\mathrm{O} 1$ & $\mathrm{X}_{\mathrm{K}}$ & $\mathrm{O} 2$
\end{tabular}

Penelitian ini dilakukan secara bertahap, yaitu: (1) Tahap Persiapan, dimana peneliti melakukan observasi di sekolah sebelum melakukan penelitian, menyusun perangkat pembelajaran dan instrumen penelitian, dan menentukan sampel yang dijadikan kelas kontrol dan eksperimen pada penelitian. (2) Tahap Pelaksanaan, dimana memberikan pre nontest pada kelas kontrol dan kelas eksperimen sebelum pembelajaran dilakukan, melaksanakan pembelajaran dengan memberikan perlakuan model inkuiri terbimbing dengan memanfaatkan aplikasi schoology di kelas eksperimen, dan pembelajaran dengan model pembelajaran inkuiri terbimbing tanpa memanfaatkan aplikasi di kelas kontrol, melakukan post nontest pada kelas kontrol dan kelas eksperimen sesudah pembelajaran. (3) Tahap Analisis Data, dimana mengolah dan menganalisis data dari hasil penelitian dengan menggunakan SPSS, melakukan uji hipotesis, kesimpulan dan saran dari penelitian yang sudah dilakukan.

\section{Intrumen, dan Teknik Pengumpulan Data}

Pengumpulan data dari penelitian ini dengan menggunakan instrumen non-test yaitu angket. Angket yang diberikan kepada siswa saat penelitian terbagi menjadi dua bagian yaitu angket minat pre non-test dan angket minat post non-test. Angket tersebut menggunakan pengukuran skala Likert di mana siswa dapat memilih jawaban dari angka 1 sampai 4 dengan kategori : 1 = Tidak Pernah, $2=$ Pernah, $3=$ Sering, $4=$ Sangat Sering. Pernyataan dalam angket tersebut sesuai dengan indikator minat yang terdiri atas 19 butir pernyataan. 
Tabel 2. Kisi-kisi Instrumen

\begin{tabular}{lll}
\hline No & Indikator Minat & Item Penyataan \\
\hline 1 & Perasaan Senang & $3,5,7,9$ \\
\hline 2 & Keterlibatan Siswa & $2,4,6,8,10$ \\
\hline 3 & Ketertarikan & $11,13,15,17,19$ \\
\hline 4 & Perhatian Siswa & $12,14,16,18,20$ \\
\hline
\end{tabular}

Teknik analisa instrumen yang digunakan sebelum instrumen digunakan dalam penelitian yaitu uji validasi isi yang dibantu oleh validator ahli, uji validasi konstruk yang diuji coba kepada siswa kelas XI SMA Pusaka 1 Jakarta sebanyak 35 siswa, dan uji reliabilitas. Dalam penelitian ini disajikan dalam deskripsi data adalah berupa distribusi frekuensi yang disajikan beserta presentasi frekuensi dan perolehan skor.

Uji persyaratan analisis dalam penelitian ini dilakukan setelah diperoleh data melalui lembar angket kepada siswa di kedua kelas sampel, dan data yang telah diperoleh tersebut, maka dilakukan pengolahan data yaitu penskoran data angket, lalu analisis data dengan uji normalitas dan homogenitas.

\section{Teknik Analisis Data}

Teknik analisis data dilakukan untuk menentukan uji hipotesis yang akan digunakan, uji hipotesis dilakukan untuk menjawab semua hipotesis dan rumusan masalah yang ingin dilakukan pada penelitian ini. Ada uji hipotesis yang dipilih yaitu uji t test dengan uji paired samples t test dan uji gain yang berbantu alat SPSS for Windows Versi 21.0 (Silaban, 2017)

\section{HASIL DAN PEMBAHASAN}

Berdasarkan hasil dari perhitungan untuk validasi konstruk, pada pernyataan pertama untuk hasil $r_{\text {hitung }}(0.258)<r_{\text {tabel }}(0.344)$ dinyatakan tidak valid, sedangkan pada 19 pernyataan lainnya semua nilai $r_{\text {hitung }}>r_{\text {tabel }}$ dan pernyataan dari nomor 2 sampai 20 dinyatakan valid, sehingga instrumen nontest berupa angket minat belajar yang diberikan kepada sampel sebagai data pre nontest dan post nontest sebanyak 19 butir pernyataan.

Untuk menganalisis uji reliabilitas dengan menggunakan instrumen yang diuji kepada populasi, di mana uji reliabilitas ini dibantu dengan alat bantu SPSS for Windows Versi 22.0, adapun syarat atau kriteria yang digunakan untuk melihat apakah data tersebut reliabel atau tidak, yaitu dengan nilai cronbach's alpha.

Tabel 3. Hasil Uji Reliabilitas

\begin{tabular}{c|c}
\hline \multicolumn{2}{c}{ Reliability Statistics } \\
\hline Cronbach's Alpha & Nof Items \\
\hline .893 & 20 \\
\hline
\end{tabular}

Berdasarkan tabel 3, jika dilihat nilai cronbach's alpha $(0.893)>0.6$ dan berdasarkan kriteria reliabilitas angket dinyatakan baik. Sehingga instrumen angket minat belajar dapat dipercaya dan layak digunakan untuk penelitian yang akan diberikan kepada sampel untuk data pre nontest dan post nontest pada kelas eksperimen dan kelas kontrol.

Hasil yang didapat dari uji normalitas berdasarkan data pre nontest pada kelas ekperimen dan kelas kontrol ditunjukan pada tabel 4. 
Tabel 4. Hasil Uji Normalitas

\begin{tabular}{|c|c|c|}
\hline \multicolumn{3}{|c|}{ Tests of Normality } \\
\hline & \multicolumn{2}{|c|}{ Kolmogorov-Smirnov $^{a}$} \\
\hline & Statistic Df & Sig. \\
\hline Kontrol-Eksperimen & .085 & $.200^{*}$ \\
\hline
\end{tabular}

Uji normalitas pada penelitian ini menggunakan alat bantu SPSS for Windows Versi 22.0 dengan rumus Kolmogorov-Smirnov ${ }^{\text {a }}$ dengan syarat jika Sig $>0,05$ maka sampel bersifat normal, jika Sig $\leq 0,05$ maka sampel bersifat tidak normal. Berdasarkan data yang didapat bahwa nilai Sig 0,200>0,05 dengan demikian sampel terdistribusi normal.

Hasil yang diperoleh dari uji homogenitas berdasarkan data pre nontest pada kelas eksperimen dan kelas kontrol ditunjukkan pada tabel 5.

Tabel 5. Hasil Uji Homogenitas

\begin{tabular}{lcccc}
\hline \multicolumn{4}{l}{ Test of Homogeneity of Variances } \\
\hline $\begin{array}{l}\text { Eksperimen } \\
\begin{array}{l}\text { Levene } \\
\text { Statistic }\end{array}\end{array}$ & $\mathrm{df1}$ & $\mathrm{df} 2$ & Sig. & $\mathrm{F}$ \\
\hline 1.477 & 8 & 16 & .241 & 1.100 \\
\hline
\end{tabular}

Uji homogenitas pada penelitian ini menggunakan alat bantu SPSS for Windows Versi 22.0 dengan rumus ANOVA levene test, dengan syarat dari nilai Levene Statistic $\mathrm{F}_{\text {hitung }}<\mathrm{F}_{\text {tabel }}$ dan jika Sig $>0,05$ maka sampel bersifat homogen. Berdasarkan hasil yang diperoleh nilai $F_{\text {hitung }}(1.10)<F_{\text {tabel }}(3.20)$ dengan taraf signifikan atau probility $95 \%(\alpha=0.05)$ dan nilai Sig $0.24>0.05$, yang berarti sampel bersifat homogen, di mana kelas eksperimen dan kelas kontrol memiliki minat belajar yang sama saat pembelajaran kimia.

Berdasarkan data pre nontest dan post nontest pada kelas eksperimen dan kelas kontrol, untuk mengukur uji parametrik dengan uji paired sample t test. Pada tabel 6 dapat dilihat uji hipotesis pada kelas eksperimen dan kelas kontrol.

Tabel 6. Hasil Uji Hipotesis Paired Sample t-test

\begin{tabular}{|c|c|c|c|c|c|c|c|c|c|}
\hline \multicolumn{10}{|c|}{ Paired Samples Test } \\
\hline \multicolumn{10}{|c|}{ Paired Differences } \\
\hline & & \multirow[t]{2}{*}{ Mean } & \multirow[t]{2}{*}{$\begin{array}{l}\text { Std. } \\
\text { Devi } \\
\text { ation }\end{array}$} & \multirow[t]{2}{*}{$\begin{array}{l}\text { Std. } \\
\text { Error } \\
\text { Mean }\end{array}$} & \multicolumn{2}{|c|}{$\begin{array}{l}95 \% \text { Confidence } \\
\text { Interval of the } \\
\text { Difference }\end{array}$} & \multirow[t]{2}{*}{$t$} & \multirow[t]{2}{*}{$D f$} & \multirow{2}{*}{$\begin{array}{l}\text { Sig. } \\
(2- \\
\text { taile } \\
\text { d) }\end{array}$} \\
\hline & & & & & Lower & Upper & & & \\
\hline Pair & Post Nontest- & 8.553 & 13,4 & 1,538 & 5,489 & 11,61 & 5,56 & 75 &, 000 \\
\hline 1 & Pre Nontest & & 07 & & & 6 & 1 & & \\
\hline
\end{tabular}

Pada tabel 6 Hasil Uji Hipotesis untuk peningkatan data pre nontest dan post nontest kelas eksperimen didapatkan $t_{\text {hitung }}$ sebesar 5.561 dan $t_{\text {tabel }} \alpha(0.05) / 2(\mathrm{df}=75)$ maka $\mathrm{t}_{\text {tabel }}=$ 2.377. Maka berdasarkan hasil tersebut, dapat dikatakan thitung $(5.561)>t_{\text {tabel }}(2.377)$. Selain itu berdasarkan nilai Sig. diperoleh $p$-value untuk kelas eksperimen adalah $0.00<0.05$.

Peningkatan minat belajar dengan memanfaatkan aplikasi schoology dapat dilihat dengan melakukan perhitungan skor gain. Berikut rata-rata skor gain pada kelas eksperimen dapat dilihat pada tabel 7 . 
Tabel 7. Perbandingan Rata-Rata Skor Gain Kelas Eksperimen dan Kontrol

\begin{tabular}{llll}
\hline Kelas & Rata-Rata Skor Gain & Kriteria Skor Gain & Kategori \\
\hline Eksperimen & 0.353 & $0.3 \leq g<0.7$ & Sedang \\
\hline Kontrol & 0.122 & $g<0.3$ & Rendah \\
\hline
\end{tabular}

Berdasarkan tabel 7, diperoleh hasil dari uji gain masing-masing kelas eksperimen dan kelas kontrol sebesar 0.353 dan 0.122 , jika dilihat berdasarkan kriteria skor gain bahwa kelas eksperimen dengan skor gain $0.3 \leq g(0.353)<0.7$ besar peningkatan minat belajar yang terjadi di kelas eksperimen pada tingkat kategori sedang, sedangkan kelas kontrol dengan skor gain $(0.122)<0.3$ besar peningkatan minat belajar yang terjadi di kelas kontrol di tingkat kategori rendah.

Peneliti memberikan perlakuan sebanyak dua kali pertemuan yang disesuaikan dengan RPP untuk masing-masing kelas. Perlakuan yang diberikan sesuai dengan sintak yang terdapat pada model pembelajaran inkuiri terbimbing dengan menggunakan aplikasi schoology sebagai media pembelajaran di kelas eksperimen, sedangkan pada kelas kontrol hanya menyesuaikan dengan sintak model pembelajaran inkuiri terbimbing tanpa menggunakan media pembelajaran.

Berdasarkan hasil paired sample $t$ test kriteria pengujian dilihat dari nilai $t$ dan nilai signifikan, di mana diperoleh bahwa nilai thitung sebesar 5.561 dan $t_{\text {tabel }}$ pada $\alpha(0.05) / 2(\mathrm{df}=$ 75) maka $t_{\text {tabel }}=2.377$, sehingga $t_{\text {hitung }}(5.561)>t_{\text {tabel }}(2.377)$ dan $p$-value $0.00<0.05$, hal ini menunjukkan bahwa terdapat peningkatan minat belajar kimia siswa dengan memanfaatkan aplikasi schoology. Berdasarkan dari hasil uji gain untuk melihat seberapa besar peningkatannya adalah untuk kelas eksperimen dengan skor gain sebesar 0.353 sedangkan kelas kontrol skor gain sebesar 0.122, sehingga jika disesuaikan dengan kriteria pada skor gain, maka kelas eksperimen dikategorikan sedang dan kelas kontrol dikategorikan rendah.

Adapun tanggapan yang diberikan siswa setelah diberikan perlakuan pada akhir pertemuan, siswa menulis tanggapan mengenai pembelajaran yang diterima dengan memanfaatkan aplikasi schoology di kolom kritik dan saran pada instrumen angket yang diberikan kepada siswa. Rata-rata siswa memberikan tanggapan bahwa dengan adanya aplikasi schoology, mereka jadi lebih mudah dan terbantu dalam proses belajar karena sudah tersedia sumbernya, dan selama ini peraturan sekolah yang memperbolehkan siswa membawa smartphone namun tidak digunakan dalam proses belajar mengajar, dengan adanya penelitian ini siswa diwajibkan menggunakan smartphone untuk belajar dan siswa menjadi tertarik.

Jika dilihat berdasarkan hasil skor uji gain peningkatan yang diperoleh pada kelas eksperimen yaitu 0.353 yang dikategorikan sedang dan kelas kontrol yaitu 0.122 yang dikategorikan rendah, berdasarkan pengamatan yang dilakukan oleh peneliti diperoleh beberapa faktor yaitu, peneliti melakukan penelitian ketika bulan ramadhan di mana sekolah membuat peraturan bahwa jam efektif kegiatan belajar mengajar lebih cepat dari 45 menit/1 jam pelajaran menjadi 30 menit/1 jam pelajaran, hal ini menyebabkan peneliti kesulitan untuk mengoptimalkan waktu untuk menerapkan aplikasi schoology untuk meningkatkan minat belajar siswa, dan siswa kurang semangat untuk belajar karena sedang menjalankan ibadah puasa sehingga siswa kurang aktif di kelas dan berdasarkan psikologi siswa agak terganggu dan kurang fokus. Faktor berikutnya, peneliti perlu melakukan sosialiasi terlebih dahulu dalam penggunaan aplikasi schoology, sehingga pada saat penelitian tidak menghabiskan banyak waktu untuk menjelaskan cara bagaimana menggunakan aplikasi tersebut. Selanjutnya, alat penunjang untuk penelitian ini adalah smartphone di mana pada saat penelitian berlangsung, tidak semua siswa membawa smartphone secara pribadi walaupun diusahakan semua siswa dapat menggunakan smarphone pada saat penelitian hal tersebut memicu berkurangnya minat karena smartphone yang mereka gunakan bukan miliki mereka sendiri sehingga ada keterbatasan dalam menggunakan aplikasi schoology tersebut. 
Melalui aplikasi schoology, dapat di lihat hasil belajar yang diperoleh siswa dari kuis yang telah mereka kerjakan pada setiap pertemuan berlangsung. Di mana diperoleh hasil belajar kimia siswa berbanding lurus dengan minat belajar yang diperoleh. Nilai kuis setiap pertemuan mengalami kenaikan meskipun tidak begitu tinggi, dapat dikatakan dalam penelitian ini bahwa jika minat belajar siswa tinggi maka hasil belajar yang diperoleh akan tinggi, begitupun sebaliknya. Karena minat belajar berbanding lurus dengan hasil belajar.

Hal ini sesuai dengan proses pembelajaran dalam penelitian karena diperlukan perasaan senang, ketertarikan, kerterlibatan siswa, dan perhatian siswa, sehingga terdapat minat siswa dalam belajar materi kimia tersebut. Siswa lebih semangat atau senang ketika siswa dilibatkan dalam mengerjakan kuis yang tersedia pada aplikasi schoology tersebut faktor ini memicu peningkatan pada minat belajar siswa, siswa lebih tertantang dengan menjawab kuis pada aplikasi schoology yang memiliki keterbatasan waktu sehingga siswa menjawab dengan sendiri tanpa melihat atau berdiskusi dengan teman lainnya.

\section{KESIMPULAN}

Terjadi peningkatan minat belajar siswa melalui pemanfaatan aplikasi schoology yang diperoleh berdasarkan uji hipotesis menggunakan paired sample $t$ test dengan $t_{\text {hitung }}(5.561)>$ $\mathrm{t}_{\text {tabel }}$ (2.377) jika dilihat dari $p$-value Sig. $0.00<0.05$. Artinya $\mathrm{H}_{\mathrm{a}}$ diterima dan $\mathrm{H}_{0}$ ditolak. Besar peningkatan minat belajar siswa melalui pemanfaatan aplikasi schoology berdasarkan perhitungan skor uji gain berada pada kategori sedang dengan skor 0.353.

\section{DAFTAR PUSTAKA}

APJII. 2018. Potret Zaman Now Pengguna \& Perilaku Internet Indonesia. APJII 23: 1.

Djamarah, S.B. 2015. Psikologi Belajar. Jakarta: Rineka Cipta.

Friedman, J., Serrano, J., Garafalo, F., dkk. (2018). What Makes Schoology Great. https://www.schoology.com, tanggal akses 12 Maret 2019 .

Linggasari, Y. 2015. Masih Banyak Siswa dan Guru Indonesia yang Gagap Teknologi. CNN Indonesia, tanggal akses 26 Maret 2019.

Napitupulu, E.L. 2012. Pemanfaatan Teknologi Informasi Belum Optimal. Kompas, tanggal akses 26 Maret 2019.

Pratama, H., \& Yusro, A. C. 2018. Implementasi WhatsApp Mobile Learning Untuk Meningkatkan Hasil Belajar Mahasiswa Pokok Bahasan Pengenalan Komponen Elektronika. Jurnal Pendidikan Fisika Dan Keilmuan (JPFK), 2(2), 65-69. http://doi.org/10.25273/jpfk.v2i2.696

Prawiradilaga, D.S., Ariani, D. dan Handoko, H. (2016). Mozaik Teknologi Pendidikan: ELearning. Jakarta: Kencana.

Rahmat, P.S. 2018. Psikologi Pendidikan. Jakarta: Bumi Aksara.

Silaban, S. 2017. Dasar-dasar Pendidikan Matematika dan Ilmu Pengetahuan Alam. Medan: Harapan Cerdas Publisher.

Simatupang, N.I., dan Sormin, E. 2020. The Effectiveness of Using Flipbook Maker to Improve the Chemistry Learning Outcomes of Senior High School Students. Jurnal Pendidikan Kimia. 12(1). 26-33. 10.24114/jpkim.v12i1.17710

Slameto. 2015. Belajar dan Faktor-Faktor Yang Mempengaruhi. Jakarta: Rineka Cipta.

Sugiyono. 2013. Metode Penelitian Pendidikan (Pendekatan Kuantitatif, Kualitatif, dan R\&D). Bandung: Alfabeta

Tigowati., Efendi, A., Budiyantom C.W. 2017. E-learning berbasis schoology dan edmodo: ditinjau dari motivasi dan hasil belajar siswa smk. Elinvo (Electronics, Informatics, and Vocational Education), 2(1), 49-58. https://doi.org/10.21831/elinvo.v2i1.16416 